\title{
Alphas in disguise: A new approach to uncovering them
}

\author{
Venkata Chinthalapati ${ }^{\mathrm{a}}$, \\ Cesario Mateus ${ }^{\mathrm{a}}$, \\ Natasa Todorovic ${ }^{\mathrm{b} *}$ \\ ${ }^{a}$ University of Greenwich, London, UK \\ ${ }^{b}$ The Centre for Asset Management Research, \\ Cass Business School, City University, London, UK
}

This version: March 2015

\begin{abstract}
Fama-French (Carhart) alphas of passive indices should be zero, but recent evidence shows otherwise. Inaccuracies of factors in the performance measurement models have been put forward as the main reason for this. Some computationally intensive solutions to factor adjustment have been proposed, but are not applicable to all benchmark indices. We propose an optimisation algorithm that makes minor adjustments to the market, size, value and momentum factors to obtain zero alphas for any benchmark index. In the sample of 1281 active and 102 passive US equity mutual funds benchmarking against S\&P500, our adjustment leads to augmentation of fund performance upwards in periods of index underperformance and downwards in periods of index outperformance. Overall, the adjusted alphas of both groups of funds are significantly negative, signalling poor performance. This is particularly pronounced for tracker funds, whose managers have not been successful in enhancing returns adequately to make-up for the costs involved in any of the sub-periods examined.
\end{abstract}

JEL classification: G10, G11,C6

Key words: Performance evaluation, non-zero benchmark alphas, optimisation algorithm, Fama-French (Carhart) factor adjustment

*Corresponding author. Tel.: +44 207040 0120. E-mail addresses: v.l.r.chinthalapati@gre.ac.uk (Chinthalapati), c.mateus@greenwich.ac.uk (Mateus), n.todorovic@city.ac.uk (Todorovic). 


\section{Introduction}

Fama and French (1993) three-factor model alpha and Carhart (1997) four-factor model alpha have been accepted as standard measures of portfolio performance among both academics and practitioners. However, a number of recent papers report non-zero three- and four-factor alphas both for the general passive market indices as well as indices/portfolios corresponding to some segments of the market, indicating the bias in the benchmark model. Nevertheless, if the performance estimation model is correctly specified, a passive benchmark index should not generate abnormal return. This is recognised by Chen and Knez (1996) who state that one of the conditions an admissible performance measure should conform to is to generate no out/under performance for all passive portfolio benchmarks that can be constructed. In this paper, we revisit the question of non-zero alphas in passive indexes and demonstrate what we believe is more intuitive and less-data intensive alternative methodology for assessing mutual fund performance.

Fama and French (1993) in their seminal paper give an account of positive alphas of large value portfolio (0.21\% per month, t-value 3.17$)$ and negative alphas of small cap growth portfolio ($0.34 \%$ per month, t-value -3.14). More recently Chan, Dimmock and Lakonishok (2009) report a significant Fama-French alpha of $-4.74 \%$ for Russell 2000 Growth index over a 13 year sample period. Moreover, they illustrate that using alternatives in performance evaluation models leads to unacceptable performance differentials. For instance, Russell 2000 Value index abnormal return goes from $3.5 \%$ when estimated in a model with market and value-weighted composite size and value factors (i.e. modifications of Fama-French factors) to $-3.18 \%$ using Wilshire size and style indices in Sharpe (1992) style model. Cremers, Petajisto and Zitzewitz (2012), CPZ hereafter, document non-zero alphas in well diversified passive US indices, such as S\&P 500 and Russell 2000 among others. They find that growth and general large cap indices exhibit significant outperformance, while value and general small cap indices significantly underperform based on Carhart (1997) four factor model alphas.

Fama and French (1993) state that the version of factors in their three-factor model is "somewhat arbitrary". A mounting body of recent evidence points that a misspecification of Fama-French market, small minus large companies returns (SMB hereafter) and high minus low book-to-market ratio company returns (HML hereafter) factors is the main reason behind existence of non-zero index alphas and biased performance estimates of Fama-French-Carhart models. The literature also suggests some methodological remedies for correcting this bias. For 
instance, CPZ propose the redesign of the factors used in US equity mutual fund performance evaluation in three aspects: 1) change the market portfolio to include US equities only; 2) replace equally weighted to value weighted SMB and HML factors; 3) following Moor and Sercu (2006) and similarly to Fama and French (2012), CPZ decompose HML factors into value premium for big and small stocks separately; further, they introduce size factors that resemble more closely size categories used in the industry: mid-cap minus large-cap and smallcap minus mid cap. Introduction of these adjustments is found to reduce alpha in the passive indices commonly used as benchmarks by US mutual funds. For a small cap index however, Russell 2000, the negative alpha still persists after the CPZ model amendments. CPZ acknowledge that although their modifications contribute towards improving Fama-FrenchCarhart models and reducing alphas in passive indices, they should not be regarded as the best possible alternative. Gregory, Tharayan and Christides (2013) perform a test of the CPZ model with value weighted factors and CPZ models with decomposed size and value factors (along standard three and four factor Fama-French-Carhart models) in the UK. They provide evidence to show that value weighted CPZ model with decomposed SMB and HML fares slightly better than other models when used to explain cross-section of UK returns of larger firms or those with small momentum tilt. Nevertheless, risk factors in any of the models, which are scrutinized in their unconditional form in this paper, are not consistently priced. Fletcher (2014) finds that conditional performance measures are more reliable than unconditional ones. The conditional CPZ seven factor model together with conditional Carhart (1997) alpha model transpire as the most reliable models in Fletcher (1994).

Another example of standard factor model alteration is in Huij and Verbeek (2009), who report that Fama-French-Carhart models underestimate performance of value and loser stocks and overestimate that of growth and winners. The authors find no evidence that such estimation error is the result of time-varying betas, inappropriate cut-off points between value/growth/small/large stocks in factor specification or differentials in expense ratios, but attribute it to miscalculation of risk factors in the models. In their search for an improved benchmark model, they suggest that error in risk factors is by and large mitigated if they are calculated using mutual fund returns universe rather than individual stock returns. The authors acknowledge that such factors are un-investable, but account for various trading restrictions and expenses mutual funds face and thus may serve as a better benchmark for mutual fund performance measurement. 
Angelidis, Giamouridis and Thessaromatis (2013) propose a new, benchmark-adjusted fourfactor model alpha obtained by replacing excess return of a fund relative to the risk-free rate with excess return relative to self-nominated benchmark in the standard Carhart four-factor model. Alphas from the benchmark-adjusted model are less negative and less statistically significant than the standard four-factor alphas.

We note several inefficiencies across the aforementioned studies. Firstly, alteration of factors in some studies requires tedious reconstruction of factors for which the historical data on equity fundamentals such as market capitalisation and book-to-market ratio is required. In some mutual fund performance tests benchmarks are derived using holdings data (see CPZ for instance). We believe that such heavy data and computational demands of altered models will discourage large number of professional money managers from using them. Second, even when those alterations are applied, alpha of passive indexes is reduced but it is not eliminated; or reduced to a minimum in one type of index but not in another. Third, all the models suggested in literature involve relatively large deviations from Fama-French-Carhart factors which are accepted as an industry standard.

In this paper, our contribution is methodological. We propose an optimisation algorithm that marginally alters the market, $\mathrm{SMB}, \mathrm{HML}$ and momentum factor in an attempt to eliminate alpha of the passive index against which the fund is benchmarked, over a period of time. Thus, it can be viewed as a simple 'correction' of the Fama-French three factor (FF3 hereafter) or Carhart four factor model to eliminate alpha persistent in a passive index, which is intuitively rather than theoretically motivated. Using optimisation, we ensure that while the factor alterations are minimal they enable us to a) eliminate alpha of the passive benchmark index, $b$ ) retain the same level of R-squared in the adjusted model to that of the standard model and c) warrant that FF3 and Carhart factor betas have identical t-statistics to those in the original model. We apply the algorithm for each time period we wish to evaluate the fund performance and make period-specific adjustments to factors. We test the model on the most commonly self-reported benchmark for the US long-only equity mutual funds in the Morningstar database - the S\&P 500 index. We make comparative analysis of our 'zero-alpha model' to the standard FF3 and Carhart model alphas by assessing the performance of 1383 US equity mutual funds reporting this index as their benchmark. Our analysis splits active funds (1281) and index trackers (102). 
We believe that our adjustment of FF3 (Carhart) factors to obtain zero S\&P500 alpha leads to more accurate performance measurement of mutual funds. Specifically, in the periods of positive FF3 (Carhart) index alphas, there is downward adjustment of active and passive fund alphas. Upward adjustment of funds' alphas occurs in the periods when S\&P500 exhibits negative FF3 (Carhart) alphas. In the overall period, the adjusted FF3 and Carhart alphas are lower than alphas of the standard models for both tracker funds and active funds. The adjustment leads to a greater change in alphas in the Carhart four factor model than in the Fama-French three factor model. In terms of performance, index funds persistently underperform in our model, generating negative adjusted alphas in the range of around 100bp per year in earlier years of our sample to $10 \mathrm{bp}$ in later years. In the overall period, their underperfomance is $-0.6 \%$ per year according to both models, significant at $1 \%$. The performance of active funds is mixed over the subperiods. In the overall sample period active funds produce negative adjusted FF3 (Carhart) alphas of $0.72 \%(0.79 \%)$ per year, significant at $1 \%$ level. On the whole, these results demonstrate poor performance of US equity mutual funds.

The remainder of the paper is organised as follows: Section 2 describes our data, Section 3 presents the methodology, Section 4 lays out the main results and Section 5 concludes the paper.

\section{Data description}

The sample includes 1383 long-only US equity mutual funds. Out of this number, 1281 are active and 102 tracker funds. The sample is free from survivorship bias, including both surviving and non-surviving funds. Mutual funds data spans from January 1992 to October 2013. Mutual fund returns, assets under management, expense ratios, information on fund's self-reported benchmark and active/passive style are sourced from Morningstar database. S\&P 500 returns including dividends are from CRSP. Fama-French-Carhart factors, namely the US market risk premium, the size factor (SMB), the value factor (HML) and the momentum factor (MOM) and are obtained from Ken French's web site ${ }^{1}$. Table 1 gives the average AUM, expense ratio, annualized returns, standard deviations, skewness and kurtosis for all funds, tracker funds and active funds separately. Tracker funds in our sample are almost twice as large (measured by their average AUM), have $0.42 \%$ lower annualized return but $1.45 \%$ lower

\footnotetext{
${ }^{1}$ http://mba.tuck.dartmouth.edu/pages/faculty/ken.french/data library.html
} 
standard deviation p.a. than active funds. Their expense ratios are also lower by 56bps. All fund returns are non-normally distributed with negative skew and kurtosis less than three.

\section{Table 1: Summary of funds characteristics}

Table shows the average AUM (in \$M), annualized returns (in \%), standard deviations (in \%), skewness and kurtosis of: all funds in the sample, active and tracker funds in Panel A and all funds arranged by AUM quintiles (from the highest (Q1) to the lowest (Q5)) in Panel B

\begin{tabular}{|l|c|c|c|c|c|c|}
\hline $\begin{array}{l}\text { Fund } \\
\text { group }\end{array}$ & AUM (\$M) & Expense Ratio & Return p.a. & St. Deviation p.a. & Skewness & Kurtosis \\
\hline All & $740,547,746$ & 1.88 & 5.18 & 17.96 & -0.52 & 1.77 \\
\hline Active & $685,441,300$ & 1.92 & 5.21 & 18.06 & -0.52 & 1.77 \\
\hline Trackers & $1,431,539,361$ & 1.36 & 4.80 & 16.61 & -0.56 & 1.77 \\
\hline
\end{tabular}

\section{Methodology}

The key contribution of this paper is in deriving and demonstrating the application of the new, intuitive methodology for correction of Fama-French-Carhart factors that leads to more accurate mutual fund performance measurement. The methodology comprises of several steps.

In Step 1 we select the time period over which we intend to evaluate the performance of a mutual fund, say period t. For that period t, we estimate the standard Fama-French three-factor and Carhart four-factor alpha of S\&P 500 index inclusive of dividends as in equation (1) and (2) respectively:

$R_{I, t}-R_{F, t}=\alpha_{S \& P}+\beta_{M} M K T_{t}+\beta_{S M B} S M B_{t}+\beta_{H M L} H M L_{t}+e_{t}$

And

$R_{I, t}-R_{F, t}=\alpha_{S \& P}+\beta_{M} M K T_{t}+\beta_{S M B} S M B_{t}+\beta_{H M L} H M L_{t}+\beta_{M O M} M O M_{t}+e_{t}$

Where $R_{I, t}-R_{F, t}$ is excess return on the S\&P500 index including dividends in period $t, R_{F}$ is the risk free rate, $\alpha_{S \& P}$ is the Fama-French (Carhart) performance estimate for S\&P500 index for period $t, M K T$ is the market risk premium, $S M B$ and $H M L$ are Fama and French (1993) size and value factors respectively, MOM is Carhart (1997) momentum factor.

In step 2, we allow the minor change in the factors $M K T_{t}, S M B_{t}, H M L_{t}$ and $M O M_{t}$ from the equations (1) and (2) by subtracting from them factor correction parameters (epsilons): $\varepsilon_{M K T}^{t}, \varepsilon_{S M B}^{t}, \varepsilon_{H M L}^{t}$, and $\varepsilon_{M O M}^{t}$ respectively. Factor correction parameters are obtained from 
optimisation process, under the following conditions: 1) adjusted FF3 (Carhart) alpha of the benchmark has to be equal to zero with lowest possible t-statistics; 2) the sum of the squared factor correction parameters is less than $10^{-8}\left(\varepsilon_{M K T}^{2}+\varepsilon_{S M B}^{2}+\varepsilon_{H M L}^{2}+\varepsilon_{M O M}^{2}<10^{-8}\right)$ and consequently 3$)$ the R-squared of the model and t-test of factor betas $\left(\beta_{M, t}, \beta_{S M B, t}, \beta_{H M L, t}\right.$, and $\beta_{M O M, t}$ ) remain the same as in the original models. The only parameter that is sensitive to the change in factors described in this step is $\alpha_{S \& P, t}$. The Appendix lays out mathematical proof of this method. One can verify, as shown in Appendix, that the intercept $\left(\alpha_{S \& P, t}\right)$ of the model after this small adjustment would be zero if and only if:

$$
\alpha_{S \& P, t}+\beta_{M, t} \varepsilon_{M K T}^{t}+\beta_{S M B, t} \varepsilon_{S M B}^{t}+\beta_{H M L, t} \varepsilon_{H M L}^{t}=0
$$

and

$\alpha_{S \& P, t}+\beta_{M, t} \varepsilon_{M K T}^{t}+\beta_{S M B, t} \varepsilon_{S M B}^{t}+\beta_{H M L, t} \varepsilon_{H M L}^{t}+\beta_{M O M, t} \varepsilon_{M O M}^{t}=0$

for Fama-French three-factor and Carhart four-factor models respectively.

In summary, step 2 solves the optimization problem in order to find the appropriate corrections to Fama-French and Carhart factors that ensure zero index alpha. Note that the solution to the optimization problem would assign either positive or negative values to epsilons $\varepsilon_{M K T}^{t}, \varepsilon_{S M B}^{t}, \varepsilon_{H M L}^{t}$, and $\varepsilon_{M O M}^{t}$. We adjust $M K T_{t}, S M B_{t}, H M L_{t}$ and $M O M_{t}$ by subtracting the corresponding $\varepsilon_{M K T}^{t}, \varepsilon_{S M B}^{t}, \varepsilon_{H M L}^{t}$, and $\varepsilon_{M O M}^{t}$ to obtain zero S\&P 500 alphas for the period examined. For example, if the solution to the optimization problem in step 2 gives $\varepsilon_{S M B}^{t}=0.00001$ and $\varepsilon_{H M L}^{t}=-0.00003$, then we adjust $S M B_{t}$ by subtracting 0.00001 from it and adjust $H M L_{t}$ by adding 0.00003 .

In the final step, Step 3, we regress the adjusted factors ( $A M K T, A S M B, A H M L$ and $A M O M$ ) against the excess returns of mutual fund $i$ in period $t$ to obtain new adjusted FF3 and Carhart four-factor model alpha :

$R_{i, t}-R_{F, t}=a_{i, t}+\beta_{i, M} A M K T_{t}+\beta_{A S M B, t} A S M B_{t}+\beta_{A H M L, t} A H M L_{t}+e_{i, t}$

And

$R_{i, t}-R_{F, t}=a_{i, t}+\beta_{i, M} A M K T_{t}+\beta_{A S M B, t} A S M B_{t}+\beta_{A H M L, t} A H M L_{t}+\beta_{A M O M, t} A M O M_{t}+e_{i, t}$ 
Where $R_{i, t}-R_{F, t}$ is excess return of a mutual fund $i$ in period $t, a_{i, t}$ is the new adjusted threefactor (equation (5)) or four-factor (equation (6)) alpha, $A M K T_{t}, A S M B_{t}, A H M L_{t}$, and $A M O M_{t}$, are Fama-French MKT, SMB HML and Carhart MOM factors adjusted by the values of factor correction parameters (epsilons) for period $t$.

The methodology for eliminating alphas (steps 1-2) can be applied for any period $t$ and any index. The methodology for assessing performance with our zero-alpha adjusted model (step 3) can be utilised for measuring performance of any portfolio in that same period $t$. We believe that our proposed methodology is not data or computationally intensive as for instance the CPZ model augmentations, it is applicable to any portfolio performance measurement setting and it leads to improved accuracy of performance evaluation.

\section{Findings}

\subsection{Presence of non-zero alphas in the benchmark index}

Figure 1 depicts the extent to which both FF3 and Carhart alphas of the S\&P 500 index deviate from zero over our sample period. The figure presents moving average of S\&P 500 FF3 and Carhart alphas estimated for rolling 3 year periods from January 1992 to October 2013. All alphas are annualised and expressed in basis points (bp). The highest alpha recorded is Carhart alpha, estimated for $1998-2000$ period and being economically significant at $2.35 \%$ per year. The lowest one is FF3 alpha of $-0.76 \%$ in the period 2005-2007.

Figure 1: Moving Average Fama-French 3 factor (FF3) and Carhart Alpha for S\&P 500

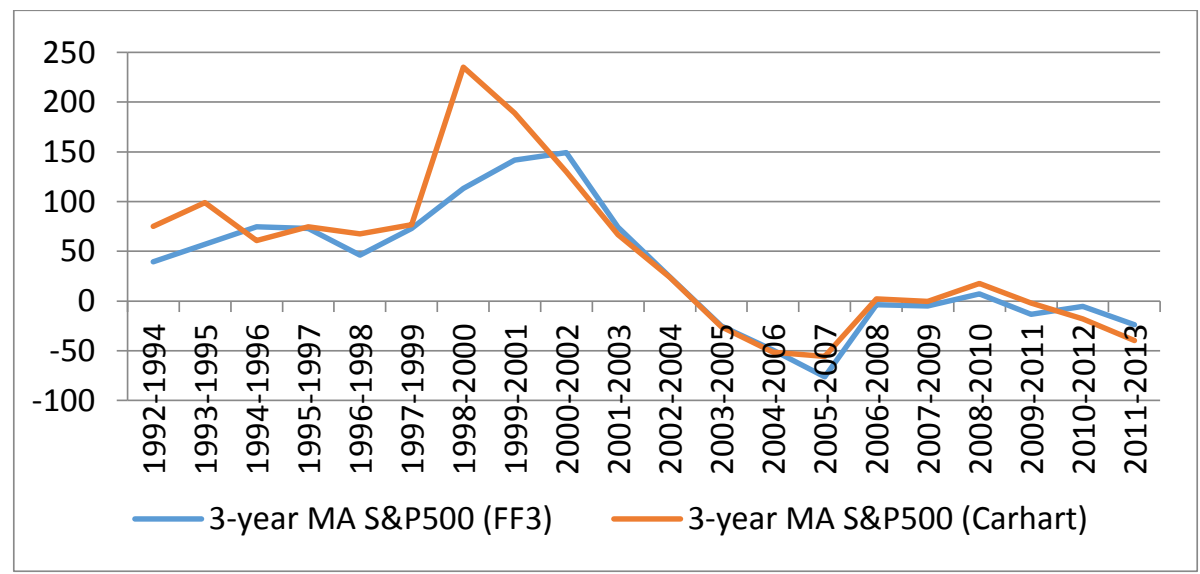


Both FF3 and Carhart alphas of the S\&P 500 index notably depart from zero in the period preceding 2008, but they do not have consistent sign: they are positive up to 2004 and negative from 2005 to 2008. In more recent years, after 2008, the deviations from zero are not sizeable, implying that greater misspecification of the FF3 and Carhart model coincides with earlier years in our sample which were mainly periods of index outperfomance. The S\&P 500 annualised FF3 alpha is $0.70 \%$ (significant at 10\% level) in the period January 1992 to December 2004, and negative (-0.22\%) albeit insignificant from January 2005 to the end of our sample. Similar to this, CPZ report FF3 alpha of $0.72 \%$ p.a. and Carhart alpha of $0.82 \%$ p.a. for S\&P 500 index in the period 1980-2005².

\subsection{Adjustments of factors}

Our adjustments to factors in either Fama-French or Carhart model are minimal, as illustrated in Figures 2a) -2d). Figures show the standard Carhart vs. adjusted Carhart MKT (2a), SMB (2b), HML (2c) and MOM (2d) factors ${ }^{3}$. Adjusted factors are obtained through optimisation process and represent the factors that will bring the value of S\&P 500 alpha to zero in the given the estimation time period.

\footnotetext{
${ }^{2} \mathrm{We}$ confirm their result for this period.

${ }^{3}$ The adjustment is minimal for FF3 model too, we do not present them here due to space considerations.
} 
Figure 2: Carhart Risk factors adjustment

2a) Market and Adjusted Market Factor

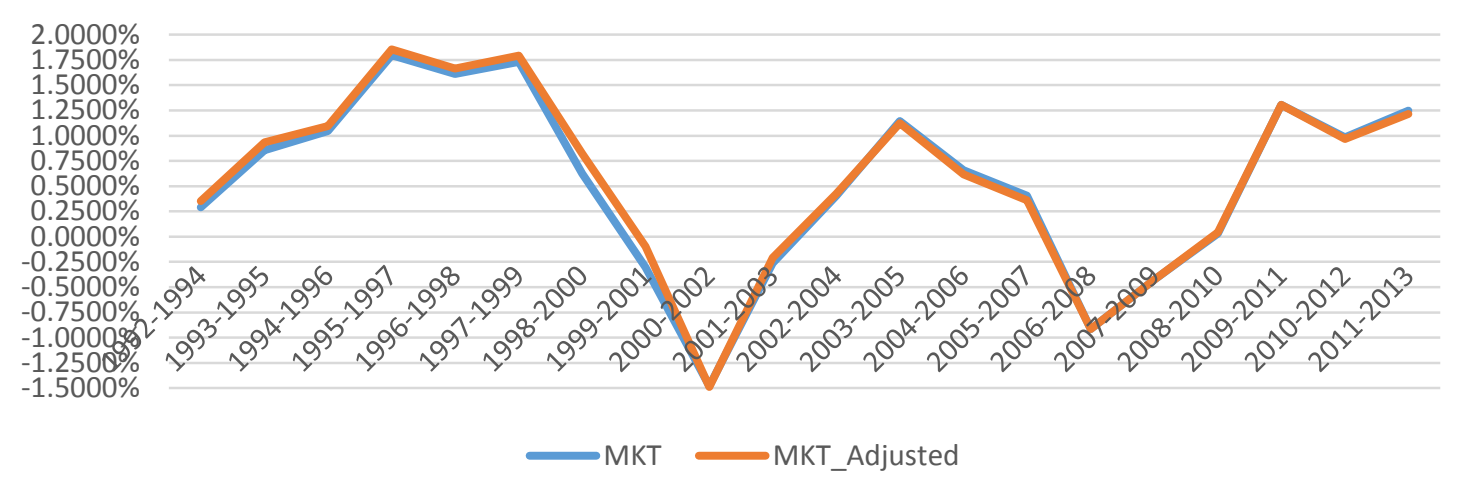

2b) SMB and Adjusted SMB Factor

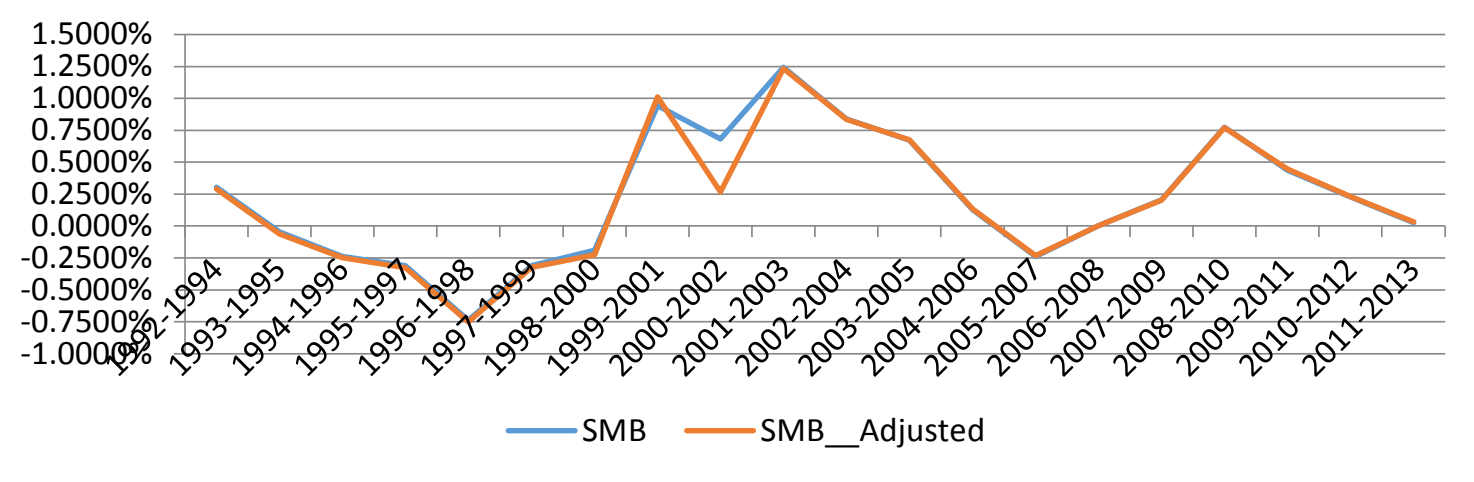

2c) HML and Adjusted HML Factor

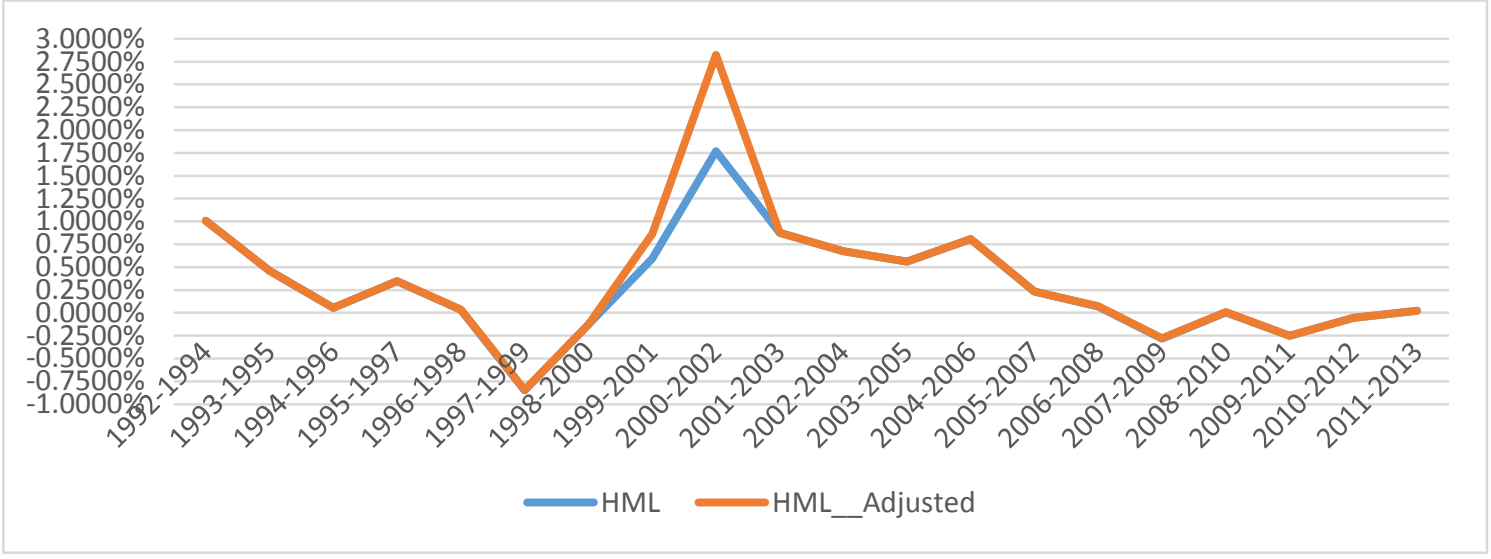

2d) MOM and Adjusted MOM Factor

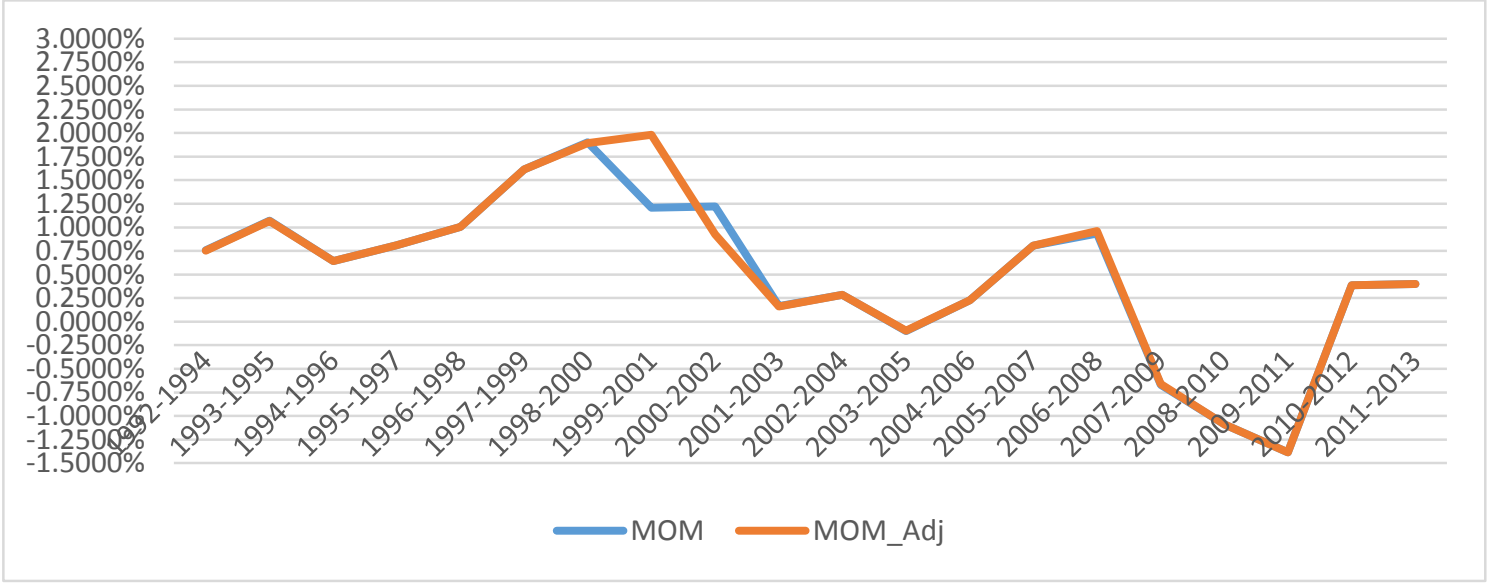




\subsection{Assessment of US mutual fund performance: Adjusted FF3 and Carhart Alphas}

Figures 3 and 4 summarise our main findings for FF3 model alpha adjustment for S\&P 500 Index and for active and passive funds respectively. Figures 5 and 6 present effects of the Carhart alpha adjustment. All figures are based on 3-year moving averages of alphas for tracker and active funds group and S\&P 500. All four figures draw to common conclusions. Specifically, when we observe positive non-adjusted S\&P 500 FF3 (Carhart) alpha, our methodological adjustment to the factor models will: 1) reduce alpha of the index to zero and 2) adjust both active and passive mutual funds alphas downward. This is expected result as mutual funds' performance is exaggerated in the standard Fama-French (Carhart) model if the index against the fund is benchmarked generates positive alpha in such model in the first place. Inverse holds when negative non-adjusted S\&P 500 Fama-French (Carhat) alphas are recorded: while the index's adjusted alpha is reduced to zero, both active and passive funds' alpha is adjusted upward. This clearly shows that our proposed adjustment of Fama-French-Carhart factors sheds new light to performance measurement and we believe leads to its improved accuracy.

Figure 3: 3-year moving average FF3 alphas and Adjusted FF3 alphas for S\&P 500 Index and all Active funds

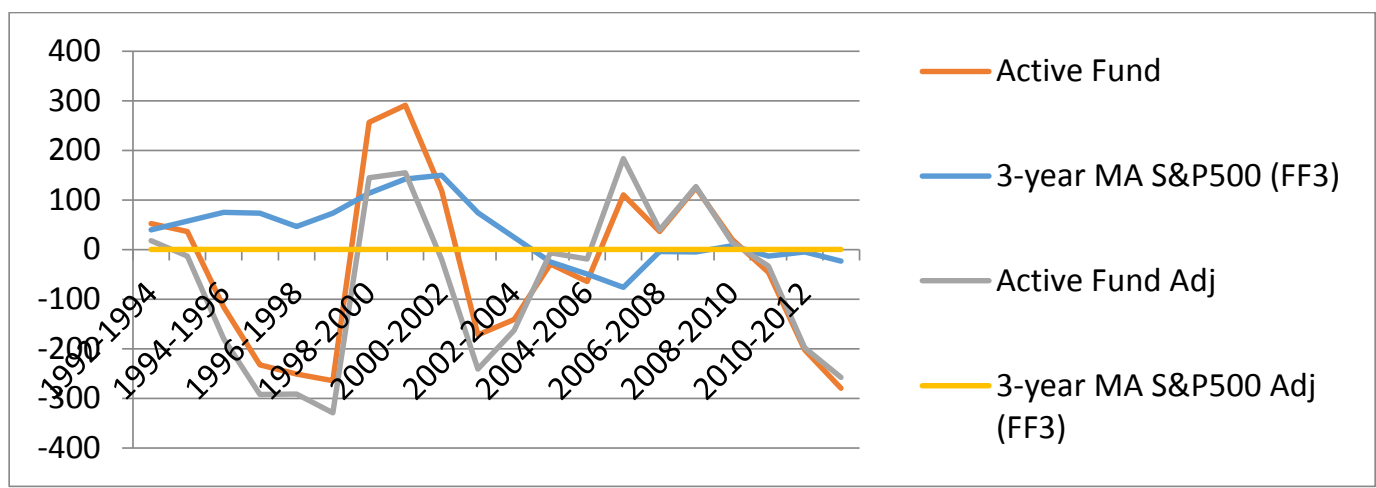

Figure 4: 3-year moving average FF3 alphas and Adjusted FF3 alphas for S\&P 500 Index and all Index funds

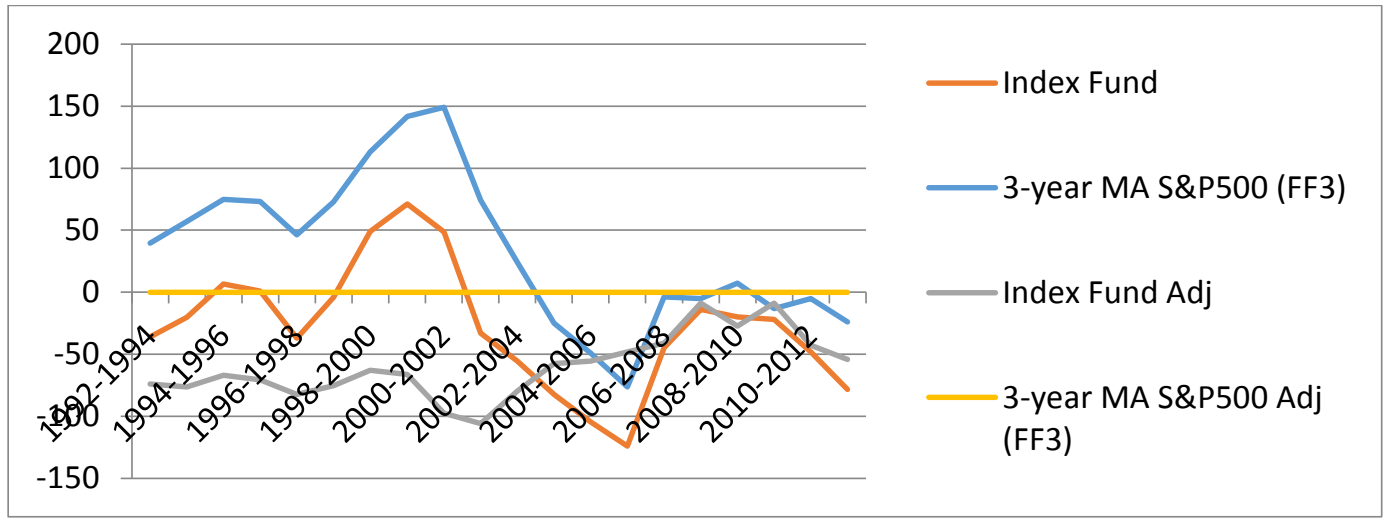


Figure 5: 3-year moving average Carhart alphas and Adjusted Carhart alphas for S\&P 500 Index and all Active funds

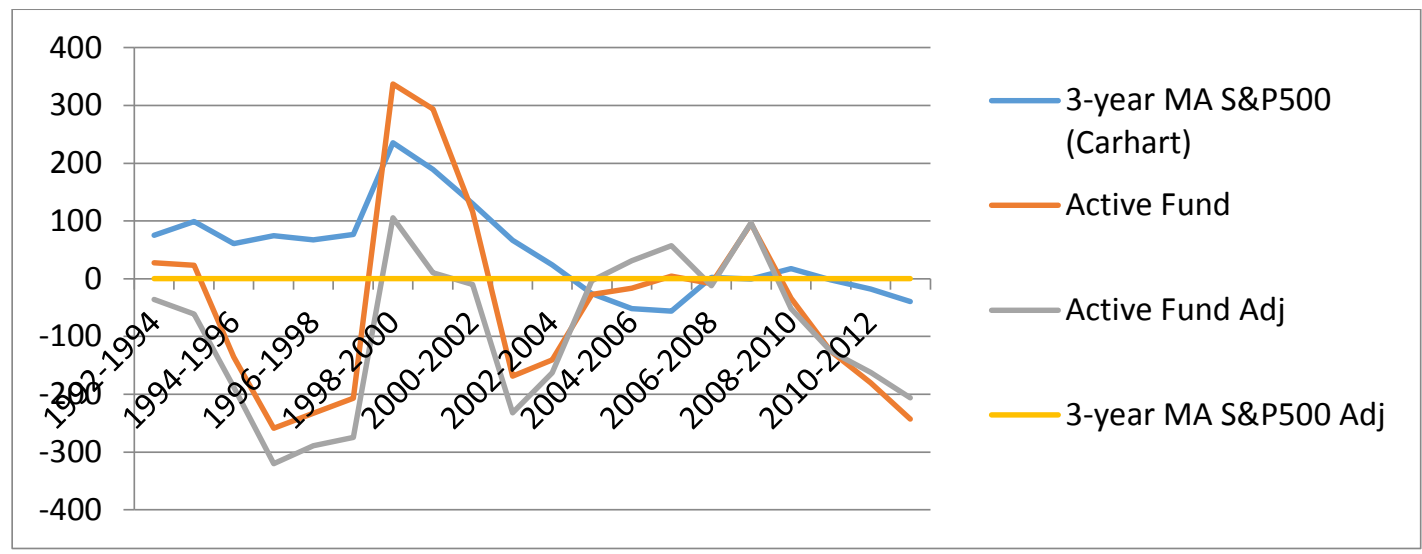

Figure 6: 3-year moving average Carhart alphas and Adjusted Carhart alphas for S\&P 500 Index and all Index funds

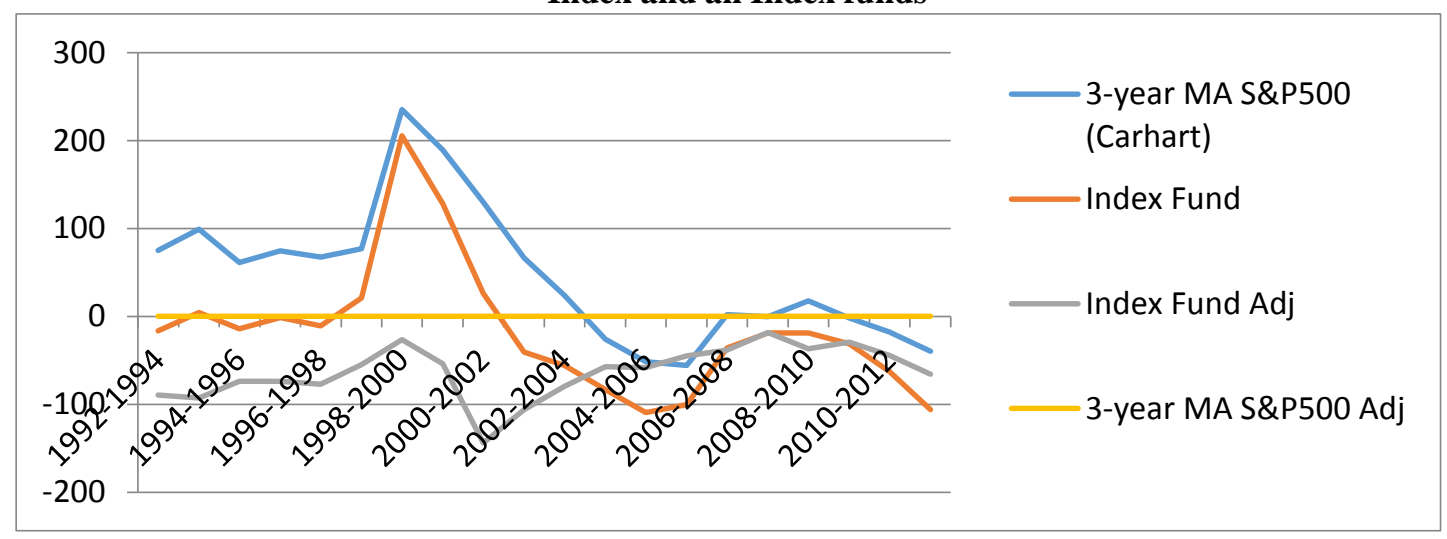

Table 2 corroborates these findings. Results presented in this table are obtained estimating a fixed effects panel for standard and adjusted FF3 model (Panel A) and standard and adjusted Carhart model (Panel B). Panels were estimated for each of the three-year non-overlapping sub-periods and the full sample period ${ }^{4}$, for tracker funds and active funds separately. We report the number of funds in each sub-period, annualised standard alphas, annualised adjusted alphas, their difference, the MKT, SMB, HML (Panel A and B) and MOM (Panel B only) coefficients from our adjusted model and R-squared of the adjusted model.

\footnotetext{
${ }^{4}$ Note that for the purpose of creating equal 3-year sub-sample periods, we do not use the last 9 months in the sub-sample analysis. Hence, the sub-sample periods are Jan 1992-Dec 1994, Jan 1995-Dec1997, Jan 1998-Dec 2000, Jan 2001-Dec 2003, Jan 2004-Dec 2006, Jan 2007- Dec 2009, Jan 2010-Dec 2012 and the full sample period is Jan 1992 - Oct 2013.
} 
Table 2: Annualised Standard vs Adjusted FF3 and Carhart Alphas for US Equity Mutual Funds

The table reports results from the following fixed effects panel regressions:

$R_{i, t}-R_{F, t}=\alpha_{i, t}+\beta_{M, t} M K T_{t}+\beta_{S M B} S M B_{t}+\beta_{H M L} H M L_{t}+e_{t}$ and $R_{i, t}-R_{F, t}=a_{i, t}+\beta_{i, M} A M K T_{t}+\beta_{A S M B, t} A S M B_{t}+\beta_{A H M L, t} A H M L_{t}+e_{i, t}$ in Panel A; $R_{i, t}-R_{F, t}=\alpha_{i, t}+$ $\beta_{M, t} M K T_{t}+\beta_{S M B} S M B_{t}+\beta_{H M L} H M L_{t}+\beta_{M O M} M O M_{t}+e_{t}$ and $R_{i, t}-R_{F, t}=a_{i, t}+\beta_{i, M} A M K T_{t}+\beta_{A S M B, t} A S M B_{t}+\beta_{A H M L, t} A H M L_{t}+\beta_{A M O M, t} A M O M_{t}+e_{i, t}$ in Panel $\mathrm{B}$. $R_{i, t}-R_{F, t}$ is excess return of a mutual fund $i$ in period $t, \alpha_{i, t}$ is the Fama-French (Panel A) or Carhart (Panel B) performance estimate, MKT is the market risk premium, $S M B$ and $H M L$ are Fama and French (1993) size and value factors respectively, MOM is Carhart (1997) momentum factor; , $a_{i, t}$ is the new Adjusted three factor (Panel A) or four factor (Panel B) alpha, $A M K T_{t}, A S M B_{t}, A H M L_{t}$, and $A M O M_{t}$, are Fama-French MKT, SMB HML and Carhart MOM factors adjusted by the values of corresponding factor correction parameters (epsilons) in period $t$. Superscript *indicate statistical significance at $0,01(* * *), 0,05(* *)$ and $0,10(*)$ percent levels.

\begin{tabular}{|c|c|c|c|c|c|c|c|c|c|}
\hline \multicolumn{10}{|c|}{ Panel A: FF3 Model Standard vs. Adjusted Annualised Alpha - Fixed effects panel model } \\
\hline Period & $\begin{array}{l}\text { Mutual Fund } \\
\text { Group }\end{array}$ & No. of Funds & $\begin{array}{c}\text { FF3 Alpha in \% } \\
\text { (t-test) }\end{array}$ & $\begin{array}{c}\text { FF3 Adjusted Alpha in \% } \\
\text { (t-test) }\end{array}$ & $\begin{array}{l}\text { Alpha change } \\
\text { (in bp) }\end{array}$ & $\begin{array}{c}\text { AMKT } \\
\text { (t-test) }\end{array}$ & $\begin{array}{l}\text { ASMB } \\
\text { (t-test) }\end{array}$ & $\begin{array}{l}\text { AHML } \\
\text { (t-test) }\end{array}$ & A_R-Squared \\
\hline \multirow[t]{2}{*}{ 1992-1994 } & Index Funds & 20 & $\begin{array}{c}-0.36 \\
(-1.04)\end{array}$ & $\begin{array}{c}-0.75 * * \\
(-2.16)\end{array}$ & -39 & $\begin{array}{l}0.97 * * * \\
(84.80)\end{array}$ & $\begin{array}{c}-0.21 * * * \\
(-18.74)\end{array}$ & $\begin{array}{l}0.03 * * * \\
(3.25)\end{array}$ & 0.91 \\
\hline & Active Funds & 294 & $\begin{array}{c}0.52 \\
(1.56)\end{array}$ & $\begin{array}{c}0.17 \\
(0.52)\end{array}$ & -35 & $\begin{array}{c}0.93^{* * *} \\
(85.31\end{array}$ & $\begin{array}{c}0.14 * * * \\
(12.99)\end{array}$ & $\begin{array}{c}0.04 * * * \\
(3.72)\end{array}$ & 0.43 \\
\hline \multirow{2}{*}{ 1995-1997 } & Index Funds & 33 & $\begin{array}{c}0.01 \\
(0.03)\end{array}$ & $\begin{array}{l}-0.70^{* *} \\
(-2.50)\end{array}$ & -71 & $\begin{array}{l}0.98 * * * \\
(130.89)\end{array}$ & $\begin{array}{l}-0.22 * * * \\
(-31.96)\end{array}$ & $\begin{array}{l}0.02 * * \\
(2.29)\end{array}$ & 0.96 \\
\hline & Active Funds & 427 & $\begin{array}{c}-2.33 * * * * \\
(-6.62)\end{array}$ & $\begin{array}{c}-2.93 * * * * \\
(-8.26)\end{array}$ & -60 & $\begin{array}{c}0.92 * * * \\
(97.07)\end{array}$ & $\begin{array}{c}0.15^{* * *} \\
(16.87)\end{array}$ & $\begin{array}{c}0.07 * * * \\
(4.97)\end{array}$ & 0.50 \\
\hline \multirow[t]{2}{*}{ 1998-2000 } & & & $\begin{array}{c}0.49 \\
(1.53)\end{array}$ & $\begin{array}{l}-0.63 * * \\
(-1.97)\end{array}$ & -112 & $\begin{array}{l}0.95^{* * * *} \\
(146.84)\end{array}$ & $\begin{array}{c}-0.18 * * * * \\
(-30.45)\end{array}$ & $\begin{array}{c}0.05^{* * * *} \\
(6.54)\end{array}$ & 0.95 \\
\hline & Active Funds & 603 & $\begin{array}{c}2.56 * * * \\
(6.46)\end{array}$ & $\begin{array}{l}1.45 * * * \\
(3.65)\end{array}$ & -112 & $\begin{array}{l}0.98 * * * \\
(123.05)\end{array}$ & $\begin{array}{l}0.09 * * * \\
(12.79)\end{array}$ & $\begin{array}{l}0.19 * * * \\
(18.37)\end{array}$ & 0.51 \\
\hline \multirow[t]{2}{*}{ 2001-2003 } & & & $\begin{array}{c}-0.33 \\
(-1.56)\end{array}$ & $\begin{array}{c}-1.06^{* * * *} \\
(-5.00)\end{array}$ & -73 & $\begin{array}{l}0.99 * * * \\
(285.58)\end{array}$ & $\begin{array}{c}-0.11 * * * \\
(-22.22)\end{array}$ & $\begin{array}{c}0.04 * * * \\
(7.83)\end{array}$ & 0.97 \\
\hline & Active Funds & 800 & $\begin{array}{c}-1.72 * * * \\
(-5.69)\end{array}$ & $\begin{array}{c}-2.41 * * * \\
(-7.98)\end{array}$ & -69 & $\begin{array}{l}0.98 * * * \\
(195.98)\end{array}$ & $\begin{array}{c}0.09 \\
(12.92)\end{array}$ & $\begin{array}{c}0.07 \\
(10.35)\end{array}$ & 0.64 \\
\hline \multirow[t]{2}{*}{ 2004-2006 } & & & $\begin{array}{c}-1.05 * * * * \\
(-8.90)\end{array}$ & $\begin{array}{c}-0.55^{* * * *} \\
(-4.76)\end{array}$ & 50 & $\begin{array}{l}1.01 * * * \\
(183.53)\end{array}$ & $\begin{array}{c}-0.15 * * * \\
(-30.20)\end{array}$ & $\begin{array}{c}0.03^{* * * *} \\
(5.91)\end{array}$ & 0.96 \\
\hline & Active Funds & 826 & $\begin{array}{c}-0.64 * * * \\
(-3.24)\end{array}$ & $\begin{array}{l}-0.20 \\
(-1.00)\end{array}$ & 44 & $\begin{array}{l}0.97 * * * \\
(103.47)\end{array}$ & $\begin{array}{c}0.16^{* * * *} \\
(18.08)\end{array}$ & $\begin{array}{c}0.07 \\
(8.25)\end{array}$ & 0.51 \\
\hline \multirow[t]{2}{*}{ 2007-2009 } & & & $\begin{array}{c}-0.14 \\
(-0.33)\end{array}$ & $\begin{array}{c}-0.09 \\
(-0.21)\end{array}$ & 5 & $\begin{array}{l}1.01 * * * \\
(141.79)\end{array}$ & $\begin{array}{c}-0.14 * * * \\
(-8.79)\end{array}$ & $\begin{array}{c}9.03^{* *} \\
(2.15)\end{array}$ & 0.92 \\
\hline & Active Funds & 782 & $\begin{array}{c}1.24 * * * \\
(5.15)\end{array}$ & $\begin{array}{c}1.27 * * * \\
(5.27)\end{array}$ & 3 & $\begin{array}{l}1.04 * * * \\
(257.08) \\
\end{array}$ & $\begin{array}{c}0.04 \\
(4.79) \\
\end{array}$ & $\begin{array}{c}-0.11 * * * \\
(-15.57) \\
\end{array}$ & 0.76 \\
\hline \multirow[t]{2}{*}{ 2010-2012 } & Index Funds & 60 & $\begin{array}{c}-0.48 \\
(-1.33)\end{array}$ & $\begin{array}{c}-0.43 \\
(-1.18)\end{array}$ & 5 & $\begin{array}{l}1.02 * * * \\
(122.59)\end{array}$ & $\begin{array}{c}-0.12 * * * * \\
(-6.83)\end{array}$ & $\begin{array}{l}-0.006 \\
(-0.40)\end{array}$ & 0.91 \\
\hline & Active Funds & 724 & $\begin{array}{l}-2.02 * * * \\
(-12.26)\end{array}$ & $\begin{array}{c}-1.98 * * * * \\
(-12.00)\end{array}$ & 4 & $\begin{array}{l}0.99 * * * \\
(260.13)\end{array}$ & $\begin{array}{c}0.046 * * * \\
(5.52)\end{array}$ & $\begin{array}{c}(-0.07 * * * \\
-0.92) \\
(-9.22)\end{array}$ & 0.81 \\
\hline \multirow[t]{2}{*}{ Full Sample } & & & $\begin{array}{c}-0.34^{* * * *} \\
(-3.32)\end{array}$ & $\begin{array}{c}-0.59 * * * \\
(-5.76)\end{array}$ & -25 & $\begin{array}{l}0.99 * * * \\
(516.60)\end{array}$ & $\begin{array}{c}-0.16 * * * \\
(-63.17)\end{array}$ & $\begin{array}{c}0.065^{* * *} \\
(24.37)\end{array}$ & 0.94 \\
\hline & Active Funds & 1281 & $\begin{array}{c}-0.49^{* * * *} \\
(-5.35) \\
\end{array}$ & $\begin{array}{c}-0.72 * * * \\
(-7.88) \\
\end{array}$ & -23 & $\begin{array}{l}0.96 * * * \\
(554.88) \\
\end{array}$ & $\begin{array}{c}0.063^{* * *} * \\
(26.54)\end{array}$ & $\begin{array}{c}0.0515^{* * * *} \\
(21.29)\end{array}$ & 0.64 \\
\hline
\end{tabular}




\begin{tabular}{|c|c|c|c|c|c|c|c|c|c|c|}
\hline \multicolumn{11}{|c|}{ Panel B: Carhart Model Adjusted Alpha - Fixed effects panel model } \\
\hline Period & $\begin{array}{l}\text { Mutual Fund } \\
\text { Group }\end{array}$ & $\begin{array}{l}\text { No. of } \\
\text { Funds }\end{array}$ & $\begin{array}{c}\text { Carhart Alpha in \% } \\
\text { (t-test) }\end{array}$ & $\begin{array}{c}\text { Carhart Adjusted } \\
\text { Alpha in \% (t-test) }\end{array}$ & $\begin{array}{l}\text { Alpha change } \\
\text { (in bp) }\end{array}$ & $\begin{array}{c}\text { AMKT } \\
\text { (t-test) }\end{array}$ & $\begin{array}{l}\text { ASMB } \\
\text { (t-test) }\end{array}$ & $\begin{array}{c}\text { AHML } \\
\text { (t-test) }\end{array}$ & $\begin{array}{c}\text { AMOM } \\
\text { (t-test) }\end{array}$ & A_R-Squared \\
\hline \multirow[t]{2}{*}{ 1992-1994 } & Index Funds & 20 & $\begin{array}{c}-0.17 \\
(-0.48)\end{array}$ & $\begin{array}{c}-0.90 * * * \\
(-2.58)\end{array}$ & -73 & $\begin{array}{l}0.98 * * * \\
(82.31)\end{array}$ & $\begin{array}{c}-0.20 * * * \\
(-18.44)\end{array}$ & $\begin{array}{l}0.04 * * * \\
(3.74)\end{array}$ & $\begin{array}{c}-0.03 * * * \\
(-2.80)\end{array}$ & 0.91 \\
\hline & Active Funds & 294 & $\begin{array}{l}0.28 \\
(0.73)\end{array}$ & $\begin{array}{l}-0.36 \\
(-0.95)\end{array}$ & -64 & $\begin{array}{c}0.92 * * * \\
(79.48)\end{array}$ & $\begin{array}{c}0.13^{* * * *} \\
(12.35)\end{array}$ & $\begin{array}{c}0.03^{* * *} \\
(3.04)\end{array}$ & $\begin{array}{c}0.04 * * * \\
(3.61)\end{array}$ & 0.43 \\
\hline \multirow[t]{2}{*}{ 1995-1997 } & Index Funds & 33 & $\begin{array}{l}-0.01 \\
(-0.04)\end{array}$ & $\begin{array}{l}-0.74 * * \\
(-2.48)\end{array}$ & -73 & $\begin{array}{l}0.98 * * * \\
(130.84)\end{array}$ & $\begin{array}{c}-0.22 * * * \\
(-29.62)\end{array}$ & $\begin{array}{c}0.02 * * \\
(2.30)\end{array}$ & $\begin{array}{l}0.002 \\
(0.27)\end{array}$ & 0.96 \\
\hline & Active Funds & 427 & $\begin{array}{c}-2.59 * * * \\
(-5.62) \\
\end{array}$ & $\begin{array}{c}-3.20 * * * \\
(-6.91)\end{array}$ & -61 & $\begin{array}{c}0.92 * * * \\
(97.11)\end{array}$ & $\begin{array}{c}0.16^{* * * *} \\
(16.66)\end{array}$ & $\begin{array}{c}0.07 * * * \\
(5.28)\end{array}$ & $\begin{array}{c}0.03 * * * \\
(2.62)\end{array}$ & 0.50 \\
\hline \multirow{2}{*}{ 1998-2000 } & Index Funds & 52 & $\begin{array}{c}2.06 * * * \\
(6.03)\end{array}$ & $\begin{array}{l}-0.27 \\
(-0.78)\end{array}$ & -232 & $\begin{array}{l}0.94 * * * \\
(149.38)\end{array}$ & $\begin{array}{c}-0.16 * * * \\
(-26.54)\end{array}$ & $\begin{array}{c}0.01 \\
(1.55)\end{array}$ & $\begin{array}{l}-0.06 * * * \\
(-10.77)\end{array}$ & 0.95 \\
\hline & Active Funds & 603 & $\begin{array}{c}3.37 * * * \\
(7.27) \\
\end{array}$ & $\begin{array}{l}1.06 * * * \\
(2.29)\end{array}$ & -231 & $\begin{array}{l}0.97 * * * \\
(120.81)\end{array}$ & $\begin{array}{c}0.10^{* * * *} \\
(13.49) \\
\end{array}$ & $\begin{array}{c}0.17 * * * \\
(14.78) \\
\end{array}$ & $\begin{array}{c}-0.03^{* * *} \\
(-4.28) \\
\end{array}$ & 0.51 \\
\hline \multirow[t]{2}{*}{ 2001-2003 } & & & $\begin{array}{l}-0.41^{*} \\
(-1.93)\end{array}$ & $\begin{array}{c}-1.06 * * * * \\
(-5.04)\end{array}$ & -147 & $\begin{array}{l}0.97 * * * \\
(208.57)\end{array}$ & $\begin{array}{c}-0.12 * * * \\
(-23.66)\end{array}$ & $\begin{array}{l}0.06^{* * * *} \\
(10.57)\end{array}$ & $\begin{array}{c}-0.03 * * * \\
(-7.65)\end{array}$ & 0.97 \\
\hline & Active Funds & 800 & $\begin{array}{c}-1.69 * * * \\
(-5.56)\end{array}$ & $\begin{array}{c}-2.32 * * * \\
(-7.68)\end{array}$ & -63 & $\begin{array}{l}0.99 * * * \\
(146.92)\end{array}$ & $\begin{array}{c}0.10^{* * * *} \\
(13.14)\end{array}$ & $\begin{array}{c}0.06^{* * *} \\
(7.96)\end{array}$ & $\begin{array}{l}0.01 * * \\
(2.54)\end{array}$ & 0.64 \\
\hline \multirow[t]{2}{*}{ 2004-2006 } & & 75 & $\begin{array}{c}-1.09^{* * * *} \\
(-9.19)\end{array}$ & $\begin{array}{c}-0.58^{* * * *} \\
(-4.92)\end{array}$ & 51 & $\begin{array}{l}1.01^{* * * *} \\
(183.54)\end{array}$ & $\begin{array}{c}-0.15 * * * \\
(-24.81)\end{array}$ & $\begin{array}{c}0.04 * * * \\
(6.36)\end{array}$ & $\begin{array}{l}-0.01 * * \\
(-2.46)\end{array}$ & 0.96 \\
\hline & Active Funds & 826 & $\begin{array}{l}-0.17 \\
(-0.83)\end{array}$ & $\begin{array}{c}0.31 \\
(1.55)\end{array}$ & 48 & $\begin{array}{l}0.97 * * * \\
(104.25)\end{array}$ & $\begin{array}{c}0.08^{* * * *} \\
(8.31)\end{array}$ & $\begin{array}{l}0.0007 \\
(0.07)\end{array}$ & $\begin{array}{l}0.11 * * * \\
(14.49)\end{array}$ & 0.52 \\
\hline \multirow[t]{2}{*}{ 2007-2009 } & & 67 & $\begin{array}{c}-0.19 \\
(-0.44)\end{array}$ & $\begin{array}{c}-0.18 \\
(-0.43)\end{array}$ & 1 & $\begin{array}{l}1.01 * * * \\
(130.99)\end{array}$ & $\begin{array}{c}-0.14 * * * * \\
(-8.81)\end{array}$ & $\begin{array}{l}0.02 * \\
(1.82)\end{array}$ & $\begin{array}{l}-0.004 \\
(-0.68)\end{array}$ & 0.92 \\
\hline & Active Funds & 782 & $\begin{array}{l}0.95 \\
(3.91)\end{array}$ & $\begin{array}{c}0.97 * * * \\
(3.98)\end{array}$ & 2 & $\begin{array}{l}1.03 * * * \\
(235.54)\end{array}$ & $\begin{array}{c}0.04 * * * \\
(4.01)\end{array}$ & $\begin{array}{l}-0.13 * * * \\
(-17.01)\end{array}$ & $\begin{array}{c}-0.02 * * * \\
(-7.03)\end{array}$ & 0.76 \\
\hline \multirow[t]{2}{*}{ 2010-2012 } & Index Funds & 60 & $\begin{array}{l}-0.63^{*} \\
(-1.71)\end{array}$ & $\begin{array}{c}-0.44 \\
(-1.21)\end{array}$ & 19 & $\begin{array}{l}1.02 * * * * \\
(122.21)\end{array}$ & $\begin{array}{c}-0.13 * * * \\
(-7.13)\end{array}$ & $\begin{array}{l}-0.01 \\
(-0.76)\end{array}$ & $\begin{array}{c}0.03 * * * \\
(2.64)\end{array}$ & 0.91 \\
\hline & Active Funds & 724 & $\begin{array}{c}-1.80^{* * * *} \\
(-10.79)\end{array}$ & $\begin{array}{c}-1.63 * * * \\
(-9.78)\end{array}$ & 17 & $\begin{array}{l}0.98 * * * \\
(257.66)\end{array}$ & $\begin{array}{c}0.06^{* * * *} \\
(6.63)\end{array}$ & $\begin{array}{c}-0.06 * * * \\
(-7.94)\end{array}$ & $\begin{array}{c}-0.04 * * * \\
(-8.85)\end{array}$ & 0.81 \\
\hline \multirow{2}{*}{ Full Sample } & Index Funds & 102 & $\begin{array}{c}-0.13 \\
(-1.28)\end{array}$ & $\begin{array}{c}-0.56^{* * * *} \\
(-5.42)\end{array}$ & -43 & $\begin{array}{l}0.98^{* * * *} \\
(479.66)\end{array}$ & $\begin{array}{c}-0.16 * * * \\
(-61.00)\end{array}$ & $\begin{array}{c}0.058^{* * * *} \\
(21.87)\end{array}$ & $\begin{array}{c}-0.025^{* * * *} \\
(-15.66)\end{array}$ & 0.94 \\
\hline & Active Funds & 1281 & $\begin{array}{c}-0.39 * * * * \\
(-4.26)\end{array}$ & $\begin{array}{c}-0.79 * * * \\
(-8.56)\end{array}$ & -40 & $\begin{array}{l}0.95 * * * \\
(516.29)\end{array}$ & $\begin{array}{c}0.065 * * * \\
(27.26)\end{array}$ & $\begin{array}{c}0.048 * * * \\
(19.69)\end{array}$ & $\begin{array}{c}-0.012 * * * \\
(-7.82)\end{array}$ & 0.64 \\
\hline
\end{tabular}


The adjusted alphas in both Panel A and Panel B are lower than the standard alphas prior to 2004 and higher thereafter, coinciding with periods of S\&P 500 outperformance and underperfomance periods respectively. Therefore, adjusting the FF3 and Carhart model to eliminate the S\&P 500's positive (negative) alphas up to the end of 2004 (from 2005) leads to downgrade (upgrade) in performance of mutual funds, as shown in Figures 3-6. In the full sample period, our adjustment leads to $43 \mathrm{bp}$ reduction in Carhart alpha (40bp FF3) of tracker funds and 25bps reduction in Carhart alpha (23bp FF3 alpha) of active funds. The greatest departure of adjusted from standard alphas occurs in the sub-period January 1998-December 2000, resulting in $1.1 \%$ lower FF3 adjusted alphas per year (Panel A) and 2.3\% p.a. lower Carhart adjusted alphas (Panel B) for all funds. Overall, the adjustment of the Carhart model leads to larger change in alpha then the adjustment of FF3 model, in most of the sub-periods and the full sample period. We also note that our adjusted alphas in majority of the cases exhibit improved statistical significance. Further investigation into significance of alphas estimated for each fund individually over the sample period ${ }^{5}$ reveals that before the adjustment there was 24 tracker funds (out of 102) with statistically significant alphas, which increased by $75 \%$ to 42 significant funds' alphas after the adjustment. The increase of significant alphas for active funds after adjustment was $5 \%$ (from 332 pre- to 350 post-adjustment out of 1281 funds), which considerably smaller than that for passive.

Reverting the analysis to US mutual fund performance, our adjusted alphas (both FF3 and Carhart) in Figure 4, Figure 6 and Table 2 reveal that index tracking funds have persistently underperformed, with negative adjusted alphas being statistically significant in five out of seven sub-periods and the full sample period. This seems counterintuitive, as one would expect passive tracker funds to have alphas of zero. However, tracker fund underperformance we record is in line with the expense ratios of this group of funds over time and it has become smaller in more recent time periods. This suggests that fund managers in US tracker funds have not been successful in enhancing the returns of those funds adequately to make-up for the costs involved. Active funds on the other hand exhibit periods of underperfomance (1995-1997, 2001-2003 and 2010-2012) but also periods of outperformance (1997-1999 and 2007-2009). Nevertheless, the negative adjusted alphas (both FF3 and Carhart) of active funds are greater in magnitude than the positive ones. In the full sample period active funds underperform by $0.72 \%$ (adjusted FF3 alpha) and $0.79 \%$ (adjusted Carhart alpha) per year. This leads us to

\footnotetext{
${ }^{5}$ This set of results for 1383 funds separately is not reported here
} 
conclude that the performance of US equity mutual funds based on our adjusted alphas is overall rather poor.

To highlight further how the misspecification of the standard FF3 or Carhart model can lead to misevaluation of fund performance, we present Figure 7 which shows percentage of funds whose FF3 alpha after the adjustment changes sign from positive to negative or vice versa in each of the sub-periods and the whole sample period.

Figure 7: Percentage of Tracker and Active funds whose FF3 alphas change sign after the model adjustment

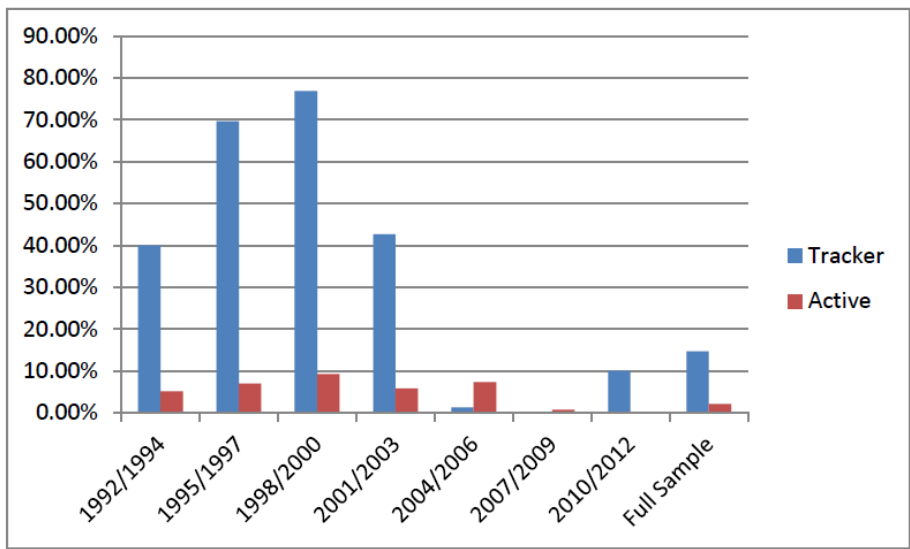

The figure illustrates that adjustment of the standard models has stronger impact on interpretation of performance of tracker funds: in the earlier years in our sample, between $40 \%$ and $77 \%$ of index funds alphas changed sign after the model adjustment. What is more, in most of the cases, the sign was changed from positive to negative. For active funds this percentage of alphas changing signs is comparatively smaller (5.1-9.3\% in the earlier sub-periods and less than $1 \%$ in some later ones). This implies that error in performance evaluation using standard models is of greater importance for passive funds: some funds that appeared to perform better than the benchmark will turn to significant underperformers after the adjustment.

Last but not least, the coefficients reported in Table 2 on the adjusted factors (AMKT, ASMB, AHML in Panel A and B and AMOM in Panel B) are by and large highly statistically significant. R-squared from the adjusted model is particularly high for index tracking funds (over 0.9). This is further emphasising the suitability of our adjusted model for evaluating fund performance. 


\section{Conclusions}

Recent evidence from the US market points that Fama-French three-factor model alphas and Carhart four-factor alphas, accepted as a fund management industry standard for performance evaluation, are not zero when calculated for the general passive market indices. This is clearly not in line with the definitions of passive benchmark characteristics used in performance measurement. While a number of studies proposes corrections to the factors in the standard Fama-French-Carhart models, those are data and computationally intensive and are not designed to eliminate alphas for all indices. Furthermore, we believe that a simpler, more intuitive approach may be more appealing for practitioners. Therefore, our contribution in this paper is methodological. We propose optimising the market, size, value and momentum factors for a given time period to a) reduce benchmark alpha to zero, b) to maintain the same R-squared to that of the original model and c) to ensure the same statistical significance of factors as in the original model. Therefore, our adjustments to the factors are minimal and can be applied to any index and over any time period.

We apply this method to eliminate the alpha of the S\&P 500 index over the period January 1992 to October 1992 and use the adjusted model to evaluate the performance of 1383 active and passive US equity mutual funds benchmarking against this index in the same period. Our findings show that our adjustment of Fama-French (Carhart) factors to obtain zero benchmark alpha leads to improved fund performance measurement: downward adjustment of active and passive fund alphas in the periods when Fama-French (Carhart) alphas of the S\&P500 index are positive and upward adjustment when the benchmark exhibits negative Fama-French (Carhart) alphas. In the overall sample period, the adjusted alphas of both active and passive funds are lower, have negative values and greater statistical significance than standard alphas. This reveals significant underperformance of US equity funds in the sample period, primarily driven by earlier years in our sample. Such underperformance is particularly pronounced among tracker funds across the sub-sample periods and the full sample.

The study could be easily extended to measure performance of any fund/portfolio benchmarking against any passive index over any period. For instance, applying the methodology to revisit assessment of performance of funds in different areas of Morningstar style box, by augmenting Fama-French-Carhart factors to eliminate alphas from relevant corresponding style indices is one possible extension. 


\section{Bibliography}

Angelidis, T., Giamouridis, D. and Tessaromatis, N., (2013), Revisiting Mutual Fund Performance Evaluation, Journal of Banking and Finance, 37 (5):1759-1776

Carhart, M. M. (1997), On persistence in mutual fund performance, Journal of Finance 52:5782.

Chan, L.K.C, Dimmock, S.G and Lakonishok J., (2009), Benchmarking money manager performance: issues and management, Review of Financial Studies, 22: 4553-4599

Chen, Z. and Knez P.J., (1996), Portfolio Performance Measurement: Theory and Applications, Review of Financial Studies, 2:511-555.

Cremers, M., Petajisto, A. and Zitzewitz, E. (2012), Should Benchmark Indices Have Alpha? Revisiting Performance Evaluation, Critical Finance Review, 2:1-48

Fama, E. F., and French, K. R. (1993), Common risk factors in the returns on stocks and bonds, Journal of Financial Economics 33:3-56.

Fama, E. F., and French, K. R. (2012), Size, value, and momentum in international stock returns, Journal of Financial Economics, 105:457-472

Fletcher, J. (2014), Benchmark models of expected returns in U.K. portfolio performance: An empirical investigation, International Review of Economics and Finance, 29: 30-46.

Gregory A, Tharayan R. and A. Christides (2013), Constructing and Testing Alternative Versions of the Fama-French and Carhart Models in the UK, Journal of Business Finance \& Accounting, 40: 172-214

Gujarati, D.N. 2003. Basic Econometrics. New York: McGraw Hill Book Co.

Huij, J.J. \& Verbeek, M.J.C.M. (2009), On the use of multifactor models to evaluate mutual fund performance, Financial Management, 38 (1): 75-102 
Moor, L.De and Sercu, P. (2006), The small firm anomaly: US and International evidence, working paper, Katholieke Universiteit Leuven

Sharpe, WF, (1992), Asset allocation: Management style and performance measurement, Journal of Portfolio Management, Winter 1992, 7-19 


\section{Appendix}

The following methodology is applicable to any finite dimensional multivariate regression analysis for the given data $Y, X_{1}, \ldots, X_{m} \in \mathfrak{R}^{n}$, where $Y$ is the dependent variable and $X_{1}, \cdots, X_{m}$ are the independent variables. $n$ represents the number of data points that we consider for the regression analysis. For clarity, we restrict ourselves by considering multivariate regression with four independent variables from Carhart's four-factor model. Let $\left(R_{S \& P, t}-R_{F, t}\right)$ be the dependent variable, in our case the risk premium of the S\&P 500 index, and $M K T, S M B_{t}, H M L_{t}, M O M_{t}$ are the independent variables in Carhart four-factor model for the given time period $t$. Let

$$
R_{S \& P, t}-R_{F, t}=\hat{\alpha}_{S \& P, t}+\hat{\beta}_{M, t} M K T_{t}+\hat{\beta}_{S M B, t} S M B_{t}+\hat{\beta}_{H M L, t} H M L_{t}+\hat{\beta}_{M O M, t} M O M_{t}
$$

be the regression model and the optimal parameters that minimize the least square error for the Euclidean norm

$$
\left\|\left(R_{S \& P, t}-R_{F, t}\right)-\left(\hat{\alpha}_{S \& P, t} 1+\hat{\beta}_{M, t} M K T_{t}+\hat{\beta}_{S M B, t} S M B_{t}+\hat{\beta}_{H M L, t} H M L_{t}+\hat{\beta}_{M O M, t} M O M M_{t}\right)\right\|_{2}^{2}
$$

are $\alpha_{S \& P, t}, \beta_{M, t}, \beta_{S M B, t}, \beta_{H M L, t}$ and $\beta_{M O M, t}$.

It is known that

$$
\left[\begin{array}{c}
\alpha_{S \& P, t} \\
\beta_{M, t} \\
\beta_{S M B, t} \\
\beta_{H M L, t} \\
\beta_{M O M, t}
\end{array}\right]=\left(X^{T} X\right)^{-1} X^{T} Y,
$$

where

$$
X=\left[\begin{array}{lllll}
1 & M K T_{t} & S M B_{t} & H M L_{t} & M O M_{t}
\end{array}\right] \in \mathfrak{R}^{n \times(4+1)} \text {, and } Y=\left(R_{S \& P, t}-R_{F, t}\right) \in \mathfrak{R}^{n} .
$$


The optimization model for the above problem is:

$(P)\left\{\begin{array}{c}\min \left\|\left(R_{S \& P, t}-R_{F, t}\right)-\left(\hat{\alpha}_{S \& P, t} 1+\hat{\beta}_{M, t} M K T_{t}+\hat{\beta}_{S M B, t} S M B_{t}+\hat{\beta}_{H M L, t} H M L_{t}+\hat{\beta}_{M O M, t} M O M_{t}\right)\right\| \\ \text { Subject to } \hat{\alpha}_{S \& P, t}, \hat{\beta}_{M, t}, \hat{\beta}_{S M B, t}, \hat{\beta}_{H M L, t}, \hat{\beta}_{M O M, t} \in \mathfrak{R} .\end{array}\right.$

Let us perturb the given data $M K T_{t}, S M B_{t}, H M L_{t}, M O M_{t}$ in order to amend the $\alpha_{S \& P, t}$ value from the above optimization problem $(P)$.

Let $\varepsilon^{t}=\left(\varepsilon_{M K T}^{t}, \varepsilon_{S M B}^{t}, \varepsilon_{H M L}^{t}, \varepsilon_{M O M}^{t}\right) \in \mathfrak{R}^{4}$ be the perturbation for the given four factors $\left(M K T_{t}, S M B_{t}, H M L_{t}, M O M_{t}\right.$ and the regression model is

$$
\begin{array}{r}
R_{S \& P, t}-R_{F, t}=\hat{\alpha}_{S \& P, t}+\hat{\beta}_{M, t}\left(\left(M K T_{t}-\varepsilon_{M K T}^{t} 1\right)+\hat{\beta}_{S M B, t}\left(S M B_{t}-\varepsilon_{S M B}^{t} 1\right)+\hat{\beta}_{H M L, t}\left(H M L_{t}-\varepsilon_{H M L}^{t} 1\right)\right. \\
+\hat{\beta}_{M O M, t}\left(M O M_{t}-\varepsilon_{M O M}^{t} 1\right)
\end{array}
$$

The associated optimal parameters according to the least square error

$$
\begin{gathered}
\left(R_{S \& P, t}-R_{F, t}\right)-\left\{\hat{\alpha}_{S \& P, t} 1+\hat{\beta}_{M, t}\left(M K T_{t}-\varepsilon_{M K T}^{t}\right)+\hat{\beta}_{S M B, t}\left(S M B_{t}-\varepsilon_{S M B}^{t}\right)+\hat{\beta}_{H M L, t}\left(H M L_{t}-\varepsilon_{H M L}^{t}\right) \|^{2}\right. \\
\left.+\hat{\beta}_{M O M, t}\left(M O M_{t}-\varepsilon_{M O M}^{t}\right)\right\}
\end{gathered} \|_{2}
$$

are

$$
\left[\begin{array}{c}
\alpha_{S \& P, t}(\varepsilon) \\
\beta_{M, t}(\varepsilon) \\
\beta_{S M B, t}(\varepsilon) \\
\beta_{H M L, t}(\varepsilon) \\
\beta_{M O M, t}(\varepsilon)
\end{array}\right]=\left((X(\varepsilon))^{T} X(\varepsilon)\right)^{-1}(X(\varepsilon))^{T} Y
$$

where

$$
\begin{aligned}
& X(\varepsilon)=\left[\begin{array}{lllll}
1 & \left(M K T_{t}-\varepsilon_{M K T}^{t} 1\right) & \left(S M B_{t}-\varepsilon_{S M B}^{t} 1\right) & \left(H M L_{t}-\varepsilon_{H M L}^{t} 1\right) & \left(M O M_{t}-\varepsilon_{M O M}^{t} 1\right)
\end{array}\right] \in \Re^{n \times(4+1)}, \\
& \text { and } Y=\left(R_{I, t}-R_{F, t}\right) \in \mathfrak{R}^{n} \text {. }
\end{aligned}
$$

The modified optimization problem for identifying the best parameters for the given $\varepsilon$ is 


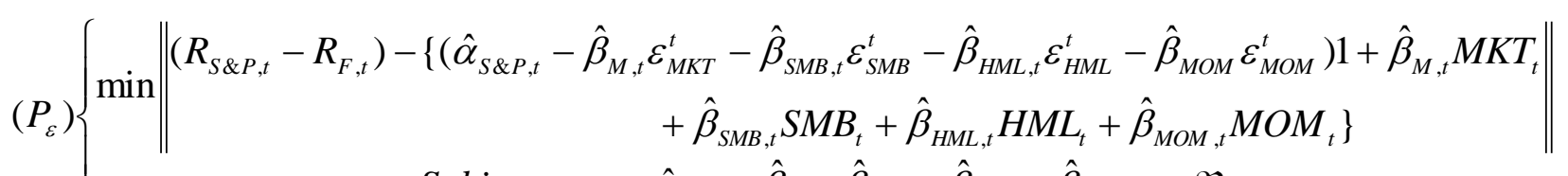
Subject to $\hat{\alpha}_{S \& P, t}, \hat{\beta}_{M, t}, \hat{\beta}_{S M B, t}, \hat{\beta}_{H M L, t}, \hat{\beta}_{M O M, t} \in \mathfrak{R}$.

It is easy to verify that the regression coefficients are intact due to the above perturbation and the only variant due to the perturbation is the intercept of the regression (Gujarati, 2003). We write this fact as the following lemmas.

Lemma 1: For the given data $\beta_{M, t}(\varepsilon)=\beta_{M, t}, \beta_{S M B, t}(\varepsilon)=\beta_{S M B, t}, \beta_{H M L, t}(\varepsilon)=\beta_{H M L, t}$ and $\beta_{M O M, t}(\varepsilon)=\beta_{M O M, t}$

Note that $\beta_{M, t}(0)=\beta_{M, t}, \beta_{S M B, t}(0)=\beta_{S M B, t}, \beta_{H M L, t}(0)=\beta_{H M L, t}$ and $\beta_{M O M, t}(0)=\beta_{M O M, t}$

Lemma 2: Least square error for both $P$ and $P_{\varepsilon}$ is the same.

Theorem 1: For the given $\beta_{M, t}, \beta_{S M B, t}, \beta_{H M L, t}$ and $\beta_{M O M, t}$, the $\alpha_{S \& P, t}(\varepsilon)=0$ if and only if $\alpha_{S \& P, t}(0)+\beta_{M, t}(0) \varepsilon_{M K T}^{t}+\beta_{S M B, t}(0) \varepsilon_{S M B}^{t}+\beta_{H M L, t}(0) \varepsilon_{H M L}^{t}+\beta_{M O M, t}(0) \varepsilon_{M O M}^{t}=0$.

\section{Proof:}

From Lemma 2,

$$
\begin{aligned}
& \left(\alpha_{S \& P, t}(0), \beta_{M, t}(0), \beta_{S M B, t}(0), \beta_{H M L, t}(0), \beta_{M O M, t}(0)\right) \quad \text { optimal } \quad \text { for } \quad(P) \Leftrightarrow \\
& \left(\alpha_{S \& P, t}(\varepsilon), \beta_{M, t}(\varepsilon), \beta_{S M B, t}(\varepsilon), \beta_{H M L, t}(\varepsilon), \beta_{M O M, t}(\varepsilon)\right) \text { optimal for }\left(P_{\varepsilon}\right) .
\end{aligned}
$$

So,

$$
\begin{gathered}
\|\left(\begin{array}{c}
\left(R_{S \& P, t}-R_{F, t}\right)-\left(\alpha_{S \& P, t}(0) 1+\beta_{M, t}(0) M K T_{t}+\beta_{S M B, t}(0) S M B_{t}\right. \\
\left.+\beta_{H M L, t}(0) H M L_{t}+\beta_{M O M, t}(0) M O M_{t}\right)
\end{array} \| \leq\right. \\
\left.\| \begin{array}{c}
\left(R_{S \& P, t}-R_{F, t}\right)-\left(\left(\hat{\alpha}_{S \& P}(\varepsilon)-\hat{\beta}_{M, t}(\varepsilon) \varepsilon_{M K T}^{t}-\hat{\beta}_{S M B, t}(\varepsilon) \varepsilon_{S M B}^{t}-\hat{\beta}_{H M L}(\varepsilon) \varepsilon_{H M L}^{t}-\hat{\beta}_{M O M}(\varepsilon) \varepsilon_{M O M}^{t}\right) 1\right. \\
\left.+\hat{\beta}_{M, t}(\varepsilon) M K T_{t}+\hat{\beta}_{S M B, t}(\varepsilon) S M B_{t}+\hat{\beta}_{H M L, t}(\varepsilon) H M L_{t}+\hat{\beta}_{M O M, t}(\varepsilon) M O M_{t}\right)
\end{array}\right)
\end{gathered}
$$


But from Lemma 1,

$$
\begin{aligned}
& \beta_{M, t}(\varepsilon)=\beta_{M, t}(0), \beta_{S M B, t}(\varepsilon)=\beta_{S M B, t}(0), \beta_{H M L, t}(\varepsilon)=\beta_{H M L, t}(0) \text { and } \beta_{M O M, t}(\varepsilon)=\beta_{M O M, t}(0) \\
& \therefore \quad \alpha_{S \& P}(0)=\alpha_{S \& P}(\varepsilon)-\left(\beta_{M, t}(0) \varepsilon_{M K T}^{t}+\beta_{S M B, t}(0) \varepsilon_{S M B}^{t}+\beta_{H M L, t}(0) \varepsilon_{H M L}^{t}+\beta_{M O M, t}(0) \varepsilon_{M O M}^{t}\right) \text { and } \\
& \alpha_{S \& P}(\varepsilon)=\alpha_{S \& P}(0)+\left(\beta_{M, t}(0) \varepsilon_{M K T}^{t}+\beta_{S M B, t}(0) \varepsilon_{S M B}^{t}+\beta_{H M L, t}(0) \varepsilon_{H M L}^{t}+\beta_{M O M, t}(0) \varepsilon_{M O M}^{t}\right) .
\end{aligned}
$$

So, $\varepsilon$ that satisfies

$$
\alpha_{S \& P}(0)+\left(\beta_{M, t}(0) \varepsilon_{M K T}^{t}+\beta_{S M B, t}(0) \varepsilon_{S M B}^{t}+\beta_{H M L, t}(0) \varepsilon_{H M L}^{t}+\beta_{M O M, t}(0) \varepsilon_{M O M}^{t}\right)=0
$$

would give the required $\alpha_{S \& P}(\varepsilon)=0$ in the multivariate linear regression.

\section{QED}

Note that there are infinite number of solutions $(\varepsilon)$ for $\alpha_{S \& P}(\varepsilon)=0$. It is important to identify the $\varepsilon$ that gives the required regression with high statistical significance. Since $t$-statistic and the associated $p$-value are depending on the $\varepsilon$ value, we solve the following optimization problem in order to get the correction parameter $\varepsilon$ that optimizes the statistical significance of the regression. Let the $t-$ statistic for $\alpha_{S \& P}(\varepsilon)$ is $t_{\alpha}$.

Then,

$$
t_{\alpha}=\frac{\left\lfloor\left(\overline{R_{S \& P, t}-R_{F, t}}\right)-\beta_{M, t}(\varepsilon) \overline{M K T_{t}}-\beta_{S M B, t}(\varepsilon) \overline{S M B_{t}}-\beta_{H M L, t}(\varepsilon) \overline{H M L_{t}}-\beta_{M O M, t}(\varepsilon) \overline{M O M_{t}}\right\rfloor}{S E\left(\alpha_{S \& P}(\varepsilon)\right)}
$$

Where $S E\left(\alpha_{S \& P}(\varepsilon)\right)$ represents the standard error of the coefficient $\alpha_{S \& P}(\varepsilon)$. Where $\left(\overline{R_{S \& P, t}-R_{F, t}}\right), \overline{M K T_{t}}, \overline{S M B_{t}}, \overline{H M L_{t}}$ and $\overline{M O M_{t}}$ represent the mean values of $\left(R_{S \& P, t}-R_{F, t}\right), M K T_{t}, S M B_{t}, H M L_{t}$ and $M O M_{t}$ respectively over the $n$ data points of the time period $t$. 
Let the vector $\hat{y}=\left(\begin{array}{c}\hat{y}_{1} \\ \vdots \\ \hat{y}_{n}\end{array}\right)$ be the fitted values for $y=\left(\begin{array}{c}\left(R_{S \& P, t}-R_{F, t}\right)_{1} \\ \vdots \\ \left(R_{S \& P, t}-R_{F, t}\right)_{n}\end{array}\right)$ and $n$ be the number of data points used for the regression estimation during the time period $t$, then the variancecovariance matrix $\hat{V}$ of $\left(\alpha_{S \& P}(\varepsilon), \beta_{M, t}(\varepsilon), \beta_{S M B, t}(\varepsilon), \beta_{H M L, t}(\varepsilon), \beta_{M O M, t}(\varepsilon)\right)$ is $\hat{V}=\left(\frac{1}{n-4-1} \sum_{i=1}^{n}\left(y_{i}-\hat{y}_{i}\right)^{2}\right)\left(X^{T}(\varepsilon) X(\varepsilon)\right)^{-1}$

Since $\operatorname{SE}\left(\alpha_{S \& P}(\varepsilon)\right)=\sqrt{\hat{V}_{1,1}}$, the $t-$ statistic for $\alpha_{S \& P}(\varepsilon)$ can be written as $t_{\alpha}=\frac{\left\lfloor\left(\overline{R_{S \& P, t}-R_{F, t}}\right)-\beta_{M, t}(\varepsilon) \overline{M K T_{t}}-\beta_{S M B, t}(\varepsilon) \overline{S M B_{t}}-\beta_{H M L, t}(\varepsilon) \overline{H M L_{t}}-\beta_{M O M, t}(\varepsilon) \overline{M O M_{t}}\right\rfloor}{\sqrt{\hat{V}_{1,1}}}$

Finding the $\varepsilon$ that ensures the $\alpha_{S \& P}(\varepsilon)$ be close to zero and insignificant is equivalent to solving the following optimization problem that finds the corrections for Carhart factors:

$\min \quad a b s\left[\frac{\left\{\left(\overline{R_{S \& P, t}-R_{F, t}}\right)-\beta_{M, t}(\varepsilon) \overline{M K T_{t}}-\beta_{S M B, t}(\varepsilon) \overline{S M B_{t}}-\beta_{H M L, t}(\varepsilon) \overline{H M L}-\beta_{M O M, t}(\varepsilon) \overline{M O M_{t}}\right\}}{\sqrt{\hat{V}_{1,1}}}\right]$

subject to $\alpha_{S \& P}(0)+\beta_{M, t}(0) \varepsilon_{M K T}^{t}+\beta_{S M B, t}(0) \varepsilon_{S M B}^{t}+\beta_{H M L, t}(0) \varepsilon_{H M L}^{t}+\beta_{M O M, t}(0) \varepsilon_{M O M}^{t}=0 \quad$ and $\left(\varepsilon_{M K T}^{t}\right)^{2}+\left(\varepsilon_{S M B}^{t}\right)^{2}+\left(\varepsilon_{H M L}^{t}\right)^{2}+\left(\varepsilon_{M O M}^{t}\right)^{2}<10^{-8}$.

Note that the second constraint in the above optimization is to ensure that the perturbations are minute enough which is required for practical purposes. 